\title{
A INCLUSÃO DOS ESTUDANTES DO PROEJA: A PERCEPÇÃO DE PROFESSORES E ALUNOS DO CAMPUS NATAL ZONA NORTE
}

\author{
F. C. VENTURA ${ }^{1}$ e I. F. CAVALCANTE ${ }^{1}$ \\ ${ }^{1}$ Instituto Federal do Rio Grande do Norte \\ E-mail: francisca@ifrn.edu.br - ilane.cavalcanti@ifrn.edu.br
}

Artigo submetido em janeiro/2012 e aceito em maio/2012

\section{RESUMO}

Neste artigo é apresentada a percepção de professores e alunos de uma turma do programa nacional de integração da educação profissional com a educação básica, na modalidade de educação de jovens e adultos (PROEJA), do técnico de nível médio integrado em manutenção de computadores. é, portanto, seu objeto, um estudo de caso realizado no instituto federal de educação, ciência e tecnologia (IFRN) - Campus Natal Zona Norte. Trata-se de um recorte da monografia intitulada Proeja como inclusão escolar: um estudo de caso sobre as necessidades especiais dos estudantes realizada como trabalho de conclusão do Curso de Especialização em Educação Profissional e Tecnológica Inclusiva a Distância do Instituto Federal de Mato
Grosso. O conteúdo do artigo enfoca, especificamente, a percepção dos sujeitos da investigação, apresentando dados de uma pesquisa qualitativa que prioriza o ambiente natural como fonte direta dos dados; os dados coletados como sendo preponderantemente descritivos e uma preocupação maior com o processo e não com o produto. Para compor essa análise, elabora-se, a princípio, uma revisão sobre o processo de inclusão, seus conceitos e sua inserção na Rede Federal de Educação Tecnológica. A seguir, observa-se a legislação que contempla a inclusão para, finalmente, apresentar a percepção de professores e estudantes de uma turma do PROEJA no Campus Natal Zona Norte sobre sua experiência.

PALAVRAS-CHAVE: Inclusão. Educação de Jovens e Adultos. Estudo de caso.

\section{INCLUSION OF PROEJA'S STUDENTS: THE PERCEPTION OF TEACHERS AND STUDENTS OF CAMPUS NATAL - ZONA NORTE}

\section{ABSTRACT}

This work focuses on the perception of teachers and students of a class of the National Program of Integração da Educação Profissional com a Educação Básica, na Modalidade de Educação de Jovens e Adultos (PROEJA), do Técnico de Nível Médio Integrado em Manutenção de Computadores. Its subject is a study of case that took place in the Instituto Federal de Educação, Ciência e Tecnologia (IFRN) - Campus Natal Zona Norte. It is also part of a monograph entitled Proeja como inclusão escolar: um estudo de caso sobre as necessidades especiais dos estudantes developed as final work to the post-graduation course of Educação Profissional e Tecnológica Inclusiva a Distância do
Instituto Federal de Mato Grosso. This article observes the point of view of teachers and students showing quantitative and qualitative data that priories their environment as a direct source of these data; that treats data as mostly descriptive, and that concerns to the process and not to the product. To compose this analysis, it firs elaborates a critic review about the concept of inclusion and its insertion on the Federal Net of Technology Education. It also observes the legislation about this subject and finally, presents the perception of teachers and students of a class from PROEJA in Campus Natal Zona Norte about their own experience.

KEY-WORDS: Inclusion. Young and Adults Education. Study of case. 


\section{A INCLUSÃO DOS ESTUDANTES DO PROEJA: A PERCEPÇÃO DE PROFESSORES E ALUNOS DO CAMPUS NATAL ZONA NORTE}

\section{INTRODUÇÃO}

Numa pesquisa descritiva "[...] o pesquisador procura conhecer e interpretar a realidade, sem nela intervir para modificá-la". (RUDIO, 1986, p. 69). Assim, ao adotar para registro a técnica de sistematização descritiva, excluiu-se a discussão e/ou crítica de conceitos e/ou práticas didático-pedagógicas decorrentes, pois se objetivava condensar idéias e conceitos sobre educação inclusiva que pudessem servir de subsídios para uma reflexão sobre o caso dos estudantes do PROEJA.

Para Truiños (1990, p. 175) o estudo de caso é "[...] considerado um dos mais relevantes tipos de pesquisa qualitativa". E, como método de pesquisa, é definido por Young $(1990$, p. 269) como sendo:

\section{[...] um conjunto de dados que descrevem uma fase ou totalidade do processo social de uma unidade, em suas várias relações internas e nas suas fixações culturais, quer seja essa unidade uma pessoa, uma família, um profissional, uma instituição social, uma comunidade ou uma nação.}

No caso específico deste artigo, trata-se de partes dos dados relativos a uma fase que corresponde às representações sociais que estão sendo construídas pelos discursos dos professores e alunos e dos tipos de necessidades especiais que podem estar interferindo na forma de ser e atuar dos sujeitos envolvidos no caso.

\section{SOBRE INCLUSÃO E SEUS PARADIGMAS}

A problemática da deficiência sempre andou ligada a crenças sobrenaturais, demoníacas e supersticiosas, que produziram dois tipos de atitudes: uma de eliminação, menosprezo e destruição e outra de proteção e assistencialismo.

A história tem demonstrado que no Brasil, assim como nos demais países do mundo, a questão da deficiência apresenta uma longa história de discriminação e exclusão. Silva (1987, p. 273), afirma que, da mesma forma que na Europa, "[...] também no Brasil a pessoa deficiente foi considerada por vários séculos dentro da categoria mais ampla dos 'miseráveis'". Os deficientes pobres segundo este autor acabaram não significando nada em termos de vida social ou política no Brasil, constituindo-se em um 'peso' para as famílias.

\footnotetext{
A atenção formal, dispensada pelo país às pessoas com deficiência iniciou-se com a criação de internatos, sendo o Imperial Instituto dos Meninos Cegos o primeiro criado no Brasil. Hoje Instituto Benjamin Constant (I. B. C.), criado no Rio de Janeiro pelo Imperador D. Pedro II, através do Decreto Imperial $n^{\circ} 1.428$, de 12/09/1854.0 segundo foi o Instituto dos Surdos Mudos, atual Instituto Nacional de Educação de Surdos (I.N.E.S.),
} 
também criado no Rio de Janeiro e oficialmente instalado em 26/09/1857. . (BRASIL/SEE, 2005, p. 27).

Ainda de acordo com esse documento, esses dois Institutos foram criados pela interferência de amigos ou de pessoas próximas ao Imperador, que atendeu às solicitações, dada a amizade que com eles mantinha. Esse tipo de prática tão comum no Brasil, naquela época, instituiu o paradigma do assistencialismo, fenômeno que determinou, desde sempre, as formas de atenção à pessoa com deficiência no país, e a educação especial, em particular (SILVA,1987).

Depois as instituições foram aos poucos assumindo a natureza de asilos, destinados ao acolhimento de pessoas inválidas.

Na visão histórica das relações com a pessoa deficiente traçada no documento citado acima, foi no século XX que se iniciou a expansão das instituições de educação especial, em decorrência da proliferação de entidades de natureza privada, de natureza assistencial.

Em relação às escolas públicas, o atendimento à pessoa com deficiência começou pela deficiência mental, com a criação de normas e a centralização do atendimento. Esse atendimento só poderia acontecer se não prejudicasse o andamento da classe.

Nos anos 50 a proliferação de entidades assistenciais privadas continuou se ampliando e com isso aumentou o número de atendimento de pessoas com deficiência. A partir dos anos 60 essa forma de enxergar o deficiente começa a ser questionada e, com isso, inicia-se um movimento de intensa reflexão, crítica e luta em defesa dos direitos humanos e dos direitos das minorias. Mesmo assim o atendimento segregado continuou.

Os princípios da Declaração Universal dos Direitos Humanos desencadearam outro conceito - o de normalização, isto é, tornar as pessoas com deficiência o mais normalmente possível, surgindo daí um novo paradigma - o Paradigma de Serviços - que buscava capacitar, habilitar ou reabilitar as pessoas com deficiência para integrá-las à sociedade, promovendo um movimento de adaptação do indivíduo com necessidades especiais ao meio em que vive, na perspectiva de torná-lo igual ou o mais próximo possível das pessoas normais. No Brasil, o movimento ampliou-se com o surgimento de "escolas especiais, centros de habilitação, centros de reabilitação, oficinas protegidas de trabalho, clubes sociais especiais, associações desportivas especiais" (SASSAKI, 1997, p. 31).

A primeira Lei de Diretrizes e Bases - LDB (Lei no 4.024/61) formaliza o compromisso do Governo para com a educação especial, dedicando o Capítulo V a essa modalidade de educação. Para tratar da questão da educação especial, "em 1971, o Ministério da Educação e Cultura (MEC) criou um Grupo Tarefa o qual produziu a proposta de criação de um órgão autônomo para tratar da Educação Especial, sendo criado em 1973, por meio do Decreto n.o 72.425, de 03/07/73 o Centro Nacional de Educação Especial (CENESP).

De acordo com o Art. 2ㅇ desse Decreto,

O CENESP atuará de forma a proporcionar oportunidades de educação, propondo e implementando estratégias decorrentes dos princípios doutrinários e políticos, que 
orientam a Educação Especial no período pré-escolar, nos ensinos de 10 e 20 graus, superior e supletivo, para os deficientes da visão, audição, mentais, físicos, educandos com problemas de conduta para os que possuam deficiências múltiplas e os superdotados, visando sua participação progressiva na comunidade.

Dessa forma, surge a perspectiva de ampliação de atendimento para diferentes deficiências e níveis de educação.

O ano de 1981, Ano Internacional da Pessoa Deficiente, veio motivar uma sociedade que clamava por transformações significativas nessa área, para debater, organizar-se, e estabelecer metas e objetivos que encaminharam novos desdobramentos importantes.

A década de 1990 iniciou-se com a aceitação política da proposta de Educação para Todos, produzida em Jomtien, Tailândia, na conferência mundial da UNESCO. Dessa proposta "emergiu a preocupação com o desenvolvimento humano, vinculando-o à educação e dando ênfase à melhoria da qualidade de vida, que tem como um dos seus suportes a satisfação das necessidades básicas de aprendizagem" (NOGUEIRA, 2001, p. 462). Essa década foi fértil em reflexões sobre a educação em nível mundial.

Em junho de 1994, em Salamanca, na Espanha, ocorreu a Conferência Mundial sobre Necessidades Educativas Especiais: Acesso e Qualidade. Nessa conferência reuniram-se mais de 300 representantes de 92 governos e 25 organizações internacionais com objetivo de:

Promover a Educação para Todos, analisando as mudanças fundamentais de políticas necessárias para favorecer o enfoque da educação integradora, capacitando realmente as escolas para atender todas as crianças, sobretudo as que têm necessidades especiais (DECLARAÇÃO DE SALAMANCA, 1994, p. 5).

Nessa conferência foi aprovada a Declaração de Salamanca, que explicita princípios, políticas e práticas sobre as necessidades educativas especiais e uma linha de ação. Por esse documento firmou-se a urgência de ações que transformem em realidade uma educação capaz de reconhecer as diferenças, promover a aprendizagem e atender as necessidades de cada estudante individualmente. Daí veio a necessidade de construção de novo paradigma - o da Inclusão - que vislumbra o atendimento às necessidades não só dos deficientes, mas de todos os cidadãos.

O Brasil adotou a proposta da declaração de Salamanca em 1994, comprometendo-se então com a construção de um sistema educacional inclusivo, especificamente no que se refere à população de alunos com necessidades educacionais especiais.

Os Parâmetros Curriculares Nacionais (PCN), publicados em 1998, vieram nortear os profissionais da Educação quanto à relação professor e aluno, no desenvolvimento de um processo de ensino e aprendizagem eficaz e significativo.

A diferença entre os Paradigmas de Serviços e o de Inclusão está no deslocamento do eixo de adaptação. Agora não deve ser mais o indivíduo que se adapta ao meio, mas o meio que deve se adaptar ao indivíduo. Assim, impõe-se a construção de espaços que se adaptem aos usos de diferentes pessoas, com ou sem deficiência, de modo a facilitar o acesso, locomoção segura e respeito a todas as pessoas. 
A inclusão escolar implica numa escola para todos aqueles que se encontram à margem do sistema educacional, independentemente de idade, gênero, etnia, condição econômica ou social, condição física ou mental.

A legislação tem contemplado a inclusão escolar de forma restritiva à população portadora de necessidades especiais, entre eles os deficientes físicos e mentais. Isso tem suscitado questionamentos da sociedade e de grupos específicos, como os agentes educacionais, pais e mesmo o público alvo, sobre a forma de operacionalizar o conceito de inclusão escolar.

Os questionamentos acerca da realidade do estudante do PROEJA têm sido de todo tipo: pedagógico, administrativo, de relacionamento, adaptação e pertencimento à escola, técnicos e conceituais, revelando dois aspectos fundamentais: a ignorância sobre as características dos estudantes da EJA com suas necessidades educativas especiais e inclusivas e o preconceito gerado a partir dessa ignorância.

A inclusão escolar passa a ser vista como um processo no qual se amplia a participação de todos os estudantes nos estabelecimentos de ensino regular. Trata-se de ressignificar a cultura, a prática e as políticas educacionais vivenciadas nas escolas para que estas possam dar respostas positivas à diversidade de seus estudantes. No Brasil, a legislação educacional relativa à problemática da educação das pessoas com necessidades especiais é percebida pela nova LDB9394/96 no momento em que esta Lei dedica um Capítulo à Educação Especial.

A Educação Especial trabalha com o paradigma da integração que considera as características do indivíduo relacionadas às suas limitações funcionais: físicas, intelectuais ou múltiplas. Essas limitações não incapacitam o indivíduo para o convívio na sociedade e no mundo produtivo, desde que se proceda a adaptações e/ou adequações nos ambientes e equipamentos por meio do uso de tecnologias assistivas, que ajudem a eliminar as barreiras que impedem a inclusão social. De acordo com Mantoan (1997, p. 145).

A noção de inclusão não é incompatível com a integração, porém institui a inserção de
uma forma mais radical, completa e sistemática. O vocabulário integração é abandonado,
uma vez que o objetivo é incluir um aluno ou um grupo de alunos que já foram
anteriormente excluídos; a meta primordial da inclusão é a de não deixar ninguém no
exterior do ensino regular, desde o começo. As escolas inclusivas propõem um modo de
se constituir o sistema educacional que considera as necessidades de todos os alunos e
que é estruturado em virtude dessas necessidades. A inclusão causa uma mudança de
perspectiva educacional, pois não se limita a ajudar somente os alunos que apresentam
dificuldades na escola, mas apóia a todos: professores, alunos, pessoal administrativo,
para que obtenham sucesso na corrente educativa geral.

Trata-se, portanto, de um processo mais amplo do que o proposto pela Escola Especial que considera o estudante com suas capacidades relativas. A Educação Inclusiva considera o estudante como cidadão, independente de suas características e limitações e, nesse caso, todos os espaços públicos devem ser construídos observando todas as características e limitações de seu povo. É uma escola para todos e não para alguns. No Brasil, a Constituição de 1988, assim como a segunda Lei de Diretrizes e Bases da Educação Nacional (LDBN) - Lei no 9.394/96, 
destacam a importância e urgência de promover-se a inclusão escolar como elemento formador da nacionalidade.

O sistema educacional federal tem envidado esforços no sentido de operacionalizar os dispositivos legais que amparam iniciativas no caminho da inclusão escolar por meio do PROEJA. Isso implica em estabelecer relações entre o paradigma de inclusão e as práticas educativas necessárias ao estudante da EJA que precisa de adaptações e adequações, se colocando pronta para o acolhimento à diversidade de seus estudantes.

Atualmente, encontra-se em processo de estudo, de reflexão, de experimentação e de busca de modelos eficazes e eficientes de educação inclusiva para nossa realidade. Nesse processo, tem-se, na rede pública, a provisão do direito de acesso ao ensino público, preferencialmente na rede regular de ensino, a toda e qualquer criança com necessidades educacionais especiais. E a rede federal de educação tecnológica tem buscado compreender melhor a inclusão, bem como tem procurado formas de participação e auto-ajuste para construir um sistema educacional brasileiro inclusivo.

A inclusão do jovem e adulto no IFRN vem tomando corpo não por uma questão meramente formal, mas porque anuncia, de maneira concreta, a possibilidade de inclusão dessa clientela na Rede Federal de Educação Tecnológica.

\section{SOBRE LEGISLAÇÃO INCLUSIVA NO BRASIL}

Com o conceito de sociedade inclusiva ou sociedade para todos, nascido da Resolução 45/95, da ONU, a inclusão escolar começa a ganhar maior reconhecimento no Brasil na década de 1990, muito embora nossa Carta Magna de 1988 tenha reafirmado o que a maioria dos textos internacionais determina sobre o paradigma da inclusão.

No Brasil, a Convenção da Guatemala foi promulgada pelo Decreto no 3.956, de outubro de 2001, fato considerado pelos especialistas como um dos mais importantes. Até então, muitas leis dispunham sobre aspectos da inclusão das pessoas com necessidades especiais, inclusive a Constituição Federativa de 1988, no momento em que assegura a todos os cidadãos os direitos sociais, especialmente aqueles portadores de deficiência, tratando do mercado de trabalho e da acessibilidade arquitetônica.

A relação entre ensino regular e especial, o transporte, a reserva de vagas em concursos públicos e em empresas com 100 ou mais funcionários, o atendimento prioritário e o reconhecimento de línguas como a Linguagem Brasileira de Sinais (LIBRAS) são assuntos contemplados pelas leis brasileiras. Um importante passo em direção à inclusão foi dado pela Lei no 7.853. Essa Lei criminaliza o preconceito quando, no inciso IV do Art. 8o, diz ser crime "recusar ou fazer cessar a matrícula de pessoa com deficiência". Inclui também penas de um a quatro anos de prisão e multa para quem descumprir as determinações legais. Ela cria, ainda, a Coordenadoria Nacional para a Integração da Pessoa Portadora de Deficiência, responsável pela Política Nacional para a Integração da Pessoa Portadora de Deficiência (CORDE). Segundo essa Lei, o órgão que deve atuar em casos caracterizados como discriminatórios em todo o território 
nacional é o Ministério Público. Lei regulamentada posteriormente pelo Decreto no 3.298 , de 1999.

Quanto à educação, a Constituição brasileira denomina o ensino especial como apoio, não podendo substituir o direito do estudante à educação compartilhada com os demais colegas, em ambiente de convivência com pessoas também diversas. (Art. 205). No entanto, a segunda Lei de Diretrizes e Bases - Lei $n^{\circ}$ 9.394/96 de educação brasileira admite a substituição do ensino regular pelo especial, criando assim, uma divergência em relação à Constituição de 1988.

O Conselho Nacional de Educação aborda a educação especial na Resolução $n^{\circ} 2$, de setembro de 2001. Esse documento estabelece as Diretrizes Básicas para a Educação Especial na Educação Básica, defendendo a instituição de escolas inclusivas, mas admite em condições extraordinárias um sistema especial, diferenciado do sistema regular, além de escolas e classes especiais, contradizendo o paradigma da inclusão. No tocante à educação profissional, essa mesma Resolução coloca que as escolas públicas e privadas de educação profissional têm as mesmas obrigações que as escolas de educação básica quanto à acessibilidade dos estudantes com deficiência.

Decreto no 3.298, de 20 de dezembro de 1999, ao tratar da Política Nacional para a Integração da Pessoa Portadora de Deficiência, estabelece mais diretrizes para a educação, saúde, desporto, trabalho, cultura, lazer, turismo, acessibilidade, habilitação e reabilitação profissional e capacitação de profissionais especializados.

São muitas as leis que discorrem sobre a questão da inclusão no Brasil, de forma que o espaço desse artigo não comportaria apresentar. Toda essa legislação sinaliza uma preocupação com questões relacionadas à inclusão social no Brasil. E, em relação à inclusão escolar, todas as legislações da Constituição Federal à LDB, passando pela resolução $n^{\circ}$. 2 reforçam a obrigação dos sistemas de ensino de fornecer aos estudantes com necessidades especiais acessibilidade física, através da eliminação de barreiras arquitetônicas; de transporte e de acessibilidade de comunicação, pelo uso de linguagens específicas, como o braile e a libras para surdos, além de recursos educativos.

Do conjunto de leis e decretos acima expostos, duas legislações podem ser consideradas mais relevantes quando se trata da defesa dos interesses das pessoas com necessidades especiais: a Constituição Federal e o Decreto no 3.956, que promulgou a Convenção da Guatemala, que atualizam o conceito de discriminação e tratam de direitos e garantias fundamentais do ser humano.

Vale salientar que muitas das leis brasileiras foram elaboradas num período histórico ainda sob forte influência do paradigma da integração, sendo necessário fazer uma interpretação progressiva de tais leis. As restrições do acesso ao ensino regular, por exemplo, presentes ainda em algumas leis e decretos, devem ser reinterpretados à luz do paradigma da inclusão.

Busca-se, a partir desse quadro conceitual e legal, estabelecer relações com o Estudo de Caso das necessidades especiais dos estudantes do PROEJA na tentativa de encontrar respostas para a questão do PROEJA. 


\section{DADOS RECOLHIDOS E ANALISADOS}

Apresenta-se, a seguir, uma série de dados recolhidos de reuniões pedagógicas e de grupo e de entrevistas a alunos do PROEJA do campus Natal Zona Norte do IFRN. Esses dados foram recolhidos da experiência desse campus com uma turma advinda de acordo firmado entre a prefeitura de Natal e a escola, que estabeleceu a entrada dos estudantes através de processo seletivo diferenciado. Esses estudantes eram oriundos do Programa ProJovem, promovido pela Prefeitura de Natal.

\subsection{De fragmentos de atas de reuniões pedagógicas (2007)}

Ata de 24.04.07

- Preocupação dos professores com o nível de conhecimento dos estudantes.

- Em Língua Portuguesa e Matemática, na percepção dos professores, a grande maioria dos estudantes da EJA é "analfabeta" em todos os sentidos.

- A hipótese dos professores era que $80 \%$ dos estudantes da EJA seriam reprovados.

Ata de 22.05.2007

- Aluno atrasado mais de 10 minutos de tolerância, só deve entrar em sala de aula com autorização da Administração Escolar.

- O Departamento Acadêmico passou nas salas em conjunto com a Psicologia alertando aos estudantes sobre as normas de comportamento.

- Os alunos da EJA não têm o hábito de ficarem concentrados dialogando e não se pode esquecer a função social da escola de educar.

- Uma aluna entrou de licença gestante.

- Alguns professores iniciaram o processo de adaptação nas ementas de suas disciplinas.

Ata 29.05 .2007

- Para os professores há necessidade urgente de proceder a uma adaptação curricular.

- Proposta de suspender o primeiro Bimestre letivo de 2007.1 para iniciar de imediato um processo de adaptação curricular.

- Solicitação dos professores de ampliação da flexibilização curricular para outras disciplinas, além de Matemática e Língua Portuguesa.

Ata de 10.07.2007

- Nova Estrutura Curricular proposta para o Ensino Integrado na Modalidade EJA.

Ata de 14.07.2007

- O aluno só pode dar entrada em requerimento para reposição de provas 
dentro do prazo de 48 (quarenta e oito) horas e com justificativa comprovada por atestado médico.

Nos fragmentos dos registros percebe-se a preocupação dos professores com o baixo nível de conhecimentos do ensino fundamental. Essa carência de conhecimentos prévios, particularmente em Língua Portuguesa e Matemática, também provocavam baixo rendimento em outras disciplinas. Por essa razão, o Campus Natal Zona Norte ampliou a carga horária dessas disciplinas na expectativa de fazer um reforço para nivelamento dos estudantes.

A problemática da pontualidade e do comportamento dos estudantes da EJA em relação ao cumprimento de normas da escola demonstra uma inadaptação para com a estrutura de funcionamento da escola de ensino regular, que não atende a especificidade da EJA.

A urgência em proceder adaptação curricular é um dos pontos mais defendidos pelos professores. O Instituto iniciou um processo de adequação curricular, começando com Língua Portuguesa e Matemática e a criação de um programa de formação Humana e cidadania de forma normatizada, conforme Matriz Curricular e, ao mesmo tempo, informalmente, ampliou a flexibilização curricular para outras disciplinas. A acessibilidade metodológica tem sido uma via de adaptação curricular para os professores.

\subsection{De fragmentos de atas de reuniões de grupo}

Ata de 15.05.07

- Não deixar os alunos entrarem em sala de aula após a tolerância dos 10 minutos de atraso.

- Alunos sem farda só podem entrar na sala de aula com autorização da Administração Escolar.

- É proibida a entrada em sala de aula com boné.

- Alunos da EJA não têm livros para estudar.

Ata de 22.05.07

- Os professores reconhecem o baixo nível de conhecimentos com que os estudantes da EJA chegam à escola.

- Professores alertam que os estudantes da EJA vão sair do IFRN discriminados em termos de conhecimentos.

- Professores solicitam que a escola reveja a forma de seleção dos estudantes da EJA.

- Professores sugerem que os estudantes passem um ano fazendo reposição de conteúdos do ensino fundamental não trabalhados.

- Professores continuam solicitando adaptação curricular para o PROEJA.

Ata de 12.06.2007

- Avaliação da EJA.

- Biologia: maior nota igual a 3,0. Para o professor de biologia, a maior dificuldade está em os alunos não saberem ler nem escrever, não terem vocabulário, não terem leitura. 
- A professora de química relata que o aluno sabe a resposta, mas não sabe escrever.

- Professor de Matemática prevê que $40 \%$ dos conteúdos de matemática do semestre não serão atingidos e os resultados apresentados pelos estudantes são semelhantes de Biologia.

Ata de 10.07.2007

- Novamente a adaptação Curricular é solicitada.

- Novas ementas para Português e Matemática são elaboradas.

- Redistribuição de conteúdos e cargas horárias em Matemática e Língua Portuguesa.

Os registros das Atas de Reuniões de Grupo confirmam uma preocupação da escola para com o cumprimento de normas internas da Instituição. Essa exigência representa uma mudança atitudinal do estudante da EJA que contradiz o paradigma da inclusão - a escola é que tem que se adaptar e não o estudante. Nesse caso, a acessibilidade atitudinal não está sendo observada. Assim, percebe-se que o paradigma da integração está mais presente na escola do que o da inclusão, considerando que o aluno é que está se esforçando para adaptar-se à escola e não a escola para acolhê-lo. Muitos dos procedimentos cobrados dos estudantes não foram cobrados em outras escolas o que, de certa forma, impõe ao estudante um esforço de adaptação a um ambiente diferente de seu contexto de vida escolar.

O nível de conhecimento do ensino fundamental que os estudantes trouxeram é discutido e refletido pelos professores. A hipótese de que os estudantes da EJA vão sair discriminados em termos de conhecimentos adquiridos demonstra que a escola pensa a igualdade tomando como referência a aprendizagem do estudante do ensino regular e assim não considera as diferenças.

A igualdade na diversidade é um princípio do paradigma de inclusão que não está sendo vivenciado em sua plenitude pela escola. $E$, dessa forma, descaracteriza a diferença do estudante da EJA. Ainda em termos da relação igualdade versus diferença constata-se que a forma como foi realizada a seleção, bem como os critérios adotados para a entrada do estudante da EJA não coincidem com os princípios do paradigma da inclusão. Esta forma de entrada diferenciada está sendo questionada pelos professores. O que pressupõe a adoção de acessibilidade programática e atitudinal.

\subsection{Dos depoimentos de alunos}

Os depoimentos transcritos a seguir foram obtidos por meio de contatos por telefone com alguns estudantes reprovados e evadidos. Ressalta-se que muitos dos telefones constantes nas fichas de matrículas dos estudantes da turma chamavam e não atendiam ou davam sinal de ocupado e outros davam como pessoa desconhecida.

Estudante 1: "Tive muita dificuldade para entender o que o professor passava em sala de aula. Era muita matéria e os professores não passavam segurança para a gente. Chegar até a eles e tirar dúvidas. Vi que não ia conseguir passar, aí desisti". 
Estudante 2: "Sou casada, moro longe e tinha que pegar dois ônibus para ir para a escola. Muitas vezes não tinha dinheiro para pagar as passagens. Tinha que acordar muito cedo para preparar o almoço da família. Era muito pesado e não deu para aguentar".

Estudante 3: "Queria muito ter continuado no CEFET, mas não tinha condições de pagar o transporte. Tentei o auxílio transporte, mas não consegui, aí abandonei".

Estudante 4: "Em 2007.1 fui reprovado. Quando cheguei na escola para renovar minha matrícula a data tinha sido encerrada e não pude mais me matricular".

Estudante 5: "Tive problemas financeiros e precisei abandonar a escola para trabalhar. Queria muito ter dado para ficar com as duas coisas, mas não deu".

Estudante 6: "Professora é muita coisa para estudar e não estou entendendo nada. Não quero ficar doida, por isso desisti".

Estudante 7: "É muita coisa para estudar e não consigo aprender. Preciso trabalhar e o tempo não dá para as duas coisas".

Estudante 8: "Estava grávida e ia ganhar neném. Como não tenho com quem deixar meu bebê, tive que abandonar a escola".

Estudante 9: "Consegui um trabalho e como estou precisando muito de trabalhar tive que deixar de estudar, pois o horário batia com o da escola".

Estudante 10: "Consegui um trabalho no horário da escola e não deu para mudar de turma".

Estudante 11: "Estou com muitos problemas na família e não tenho cabeça para estudar".

Estudante 12: "Estou grávida com problemas de saúde. Preciso me cuidar."

Estudante 13: "Não tenho nada a reclamar dos professores. São todos muito preparados e ensinam muito bem. Eu é que não consigo aprender. Vi que ia ser reprovado mesmo, aí abandonei".

Estudante 14: "Casei e preciso trabalhar. Não deu para continuar estudando. Queria muito poder continuar". 
Estudante 15: "Tive que abandonar a escola por problema de saúde".

Estudante 16: "Estava mesmo reprovado, aí abandonei".

Estudante 16: "Eu já ia mesmo repetir o ano, aí deixei de ir para a escola".

O conteúdo da fala dos estudantes reforça a especificidade do estudante da EJA. A situação de vida irregular do público da EJA continua dificultando o sucesso de projetos educativos inclusivos, especialmente quando esses projetos tentam adaptar o estudante da EJA a uma escola de ensino regular. O paradigma da inclusão escolar determina que a escola é que tem de se adaptar ao estudante com necessidades especiais. E o estudante da EJA é um estudante com necessidades especiais.

Os depoimentos dos estudantes da turma investigada sinalizam para uma adaptação da escola em relação às acessibilidades inclusivas. Percebe-se nos argumentos dos sujeitos que muitas das evasões estão relacionadas às questões de acessibilidade, particularmente, a programática, a metodológica, a atitudinal.

\subsection{Do diálogo PROEJA}

Esse diálogo corresponde à fala dos estudantes que ainda estão freqüentando o Curso investigado. A Coordenação Nacional do PROEJA solicitou ao IFRN que realizassem um diálogo com os alunos do PROEJA a fim de avaliar o andamento da execução do programa e, ao mesmo tempo, trocar experiências entre os diferentes atores.

O Campus Natal Zona Norte iniciou tal "Diálogo" a partir de um planejamento coletivo e colaborativo entre o Departamento Acadêmico e os Setores da Pedagogia, Serviço Social e Psicologia.

Para a metodologia da execução dessa tarefa, a idéia, num primeiro momento, foi ouvir o estudante da EJA, o que implicou na elaboração e aplicação de um questionário que foi respondido por todos os estudantes matriculados em cursos do PROEJA. Dentre os dados recolhidos desse questionário, foram selecionados os mais relevantes do ponto de vista do estudante para o estudo.

Questionados sobre que necessidades especiais estão causando dificuldades na aprendizagem os estudantes destacaram:

- 21,70\% falta de tempo para estudar por trabalhar;

- 4,30\% rapidez do professor ao ensinar;

- 10,90\% problemas familiares;

- 10,90\% financeiras;

- 4,30 ter mais conhecimentos;

$-$

Os argumentos apresentados pelos estudantes para a questão: Como você avalia a carga horária das disciplinas do curso? Foram: 
- $17,40 \%$ regular;

- 63,10 boa;

- 19,50 ótima.

$-$

Para a questão que avalia o tempo de duração do curso os dados obtidos foram:

- $27,30 \%$ regular;

- 47,70\% bom;

- 25,00\% ótimo.

$-$

Sobre o processo ensino e aprendizagem, os estudantes apontam:

\section{Pontos Positivos}

- $44 \%$ professores de qualidade;

- 26\% nível de ensino;

- $4, \%$ escola com interesse no aluno;

- 4\% aperfeiçoamento;

- $6 \%$ bom em todos os aspectos;

- $8 \%$ cobrança;

- $8 \%$ outros

\section{Pontos Negativos}

- 6,00\% falta de interesse de alguns professores;

- $21 \%$ ensino difícil;

- 6\% carga horária pequena;

- 15,20\% Educação Física;

- 21,00\% muita exigência;

- 30,30\% dificuldade de aprendizagem;

- 6,00\% falta de segurança;

- 6,00\% alimentação;

- 25,20\% outros;

- 18,20\% nenhum.

$-$

Questionados sobre o que a escola ou o PROEJA pode fazer para resolver problemas de aprendizagem, as respostas foram:

- 4,45\% diminuir a carga horária de algumas disciplinas;

- 2,20\% criar linhas de transporte;

- 8,90\% mais interesse dos professores pela EJA;

- 2,20\% ser mais flexível com faltas e horários;

- $11,10 \%$ mais interação aluno-professor;

- 4,45\% professor explicar com mais clama;

- 4,45\% grupos de leitura/oficinas de redação;

- $8,90 \%$ oferecer mais recursos/incentivos; 
- 8,90\% nada;

- 13,34\% outros;

- 31,11\% não responderam.

$-$

Sugestões apresentadas pelos estudantes para melhoria do processo de ensino aprendizagem:

- 4,00\% melhorar a Matriz Curricular;

- $17,00 \%$ professor ensinar com mais calma, escrever;

- 4,00\% aulas de Educação Física mais atrativas;

- 8,00\% incentivo à prática esportiva;

- 4,00\% aulas de campo;

- 4,00\% melhoria do espaço físico;

- 6,00\% mais prática;

- 12,00\% outros;

- 41\% não responderam.

$-$

Para o processo de avaliação da escola foram atribuídos os resultados:

- 20,00\% ótimo;

- $8,90 \%$ muito bom;

- 33,30 bom;

- 11,11\% mudar;

- 4,44\% exigente demais;

- 15,55\% não respondeu;

- 6,70\% outros;

- 17,40\% nenhuma;

- 21,75 não responderam.

$-$

No primeiro período, as disciplinas em que tiveram mais dificuldades foram:

- 28,73\% Português;

- 25,30\% Matemática;

- 1,15\% Formação Humana;

- 11,50\% Filosofia;

- 24,13\% informática;

- 28,73\% Artes.

Pelos dados desse "Diálogo", as necessidades especiais confirmadas estão em consonância com a especificidade desse público. A falta de tempo para estudar por motivo de trabalho foi o aspecto mais apontado pela turma (necessidades de mais tempo); seguido de problemas familiares e financeiros.

Quando o estudante coloca que tem necessidade de mais conhecimento, demonstra ter consciência de suas limitações em termos de conhecimentos do ensino fundamental; ao colocar a 
rapidez na forma de ensinar do professor o estudante do PROEJA confirma a necessidade de mudança metodológica.

Para a maioria da turma, a duração do curso e a carga horária foram colocadas como boa e ótima. Os pontos positivos mais destacados são a qualidade dos professores e o nível de ensino da escola e os negativos foram atribuídos à dificuldade de aprendizagem e a um ensino muito exigente e difícil.

Para responder a pergunta sobre como resolver os problemas de aprendizagem, quase a metade da turma não soube responder, mesmo assim, houve destaque para mais interação entre aluno-professor, mais interesse do professor pela EJA e mais incentivo financeiro. Um dado interessante que confirma a deficiência em Língua Portuguesa foi a não resposta dada às questões subjetivas do questionário. Muitos estudantes deixaram essas questões em branco, talvez por falta do domínio da escrita.

Quanto às sugestões solicitadas aos estudantes para a melhoria do processo de ensino e aprendizagem no PROEJA, mais uma vez, muitos dos estudantes não responderam. As sugestões mais destacadas estão relacionadas à acessibilidade metodológica (professor ensinar com mais calma) e acessibilidade programática (melhorar a Matriz Curricular).

O sistema de avaliação foi concebido pela maioria dos estudantes como ótimo e bom. Mesmo assim, os referenciais do PROEJA apontam para um pensar sobre a avaliação que remeta a processos que envolvem reflexões, discussões, críticas e busca de transformações.

As disciplinas que os estudantes mais tiveram dificuldades no Primeiro Período foram: Português, Artes, Matemática, Informática e Filosofia. A falta de domínio das competências básica de leitura, escrita e da Matemática, constatadas pelos professores, pode ter sido um dos fatores para insucesso nas demais disciplinas apontadas pelos estudantes.

\section{CONSIDERAÇÕES FINAIS}

Louva-se o surgimento dessa nova modalidade de educação no Brasil por ter permitido a inclusão escolar de jovens e adultos da EJA na Rede Federal de Educação Tecnológica do país. Trata-se de uma tentativa de integração da educação profissional com a educação básica nessa modalidade de ensino, necessária para uma camada da população que por diferentes motivos foi excluída do sistema regular de ensino e isso tem dificultado sua inserção no universo do trabalho. Como diz Severino (1994, p.98), "o Homem só é plenamente cidadão se compartilha efetivamente dos bens que constituem os resultados de sua tríplice prática histórica" - trabalho, significação simbólica e relações políticas. Para o usufruto do trabalho, num mundo cada vez mais exigente e competitivo, o PROEJA, como política de inclusão escolar que tem como objetivo a elevação do nível de escolaridade dessa gente, possibilitaria a inclusão social.

Como a sala de aula é o grande termômetro pelo qual se mede o grau das mudanças educacionais e, também, micro espaço no qual as reformas educativas, verdadeiramente, se efetivam ou fracassam, o PROEJA, como inclusão escolar no IFRN - Campus Natal Zona Norte, neste estudo de caso, continua sendo um desafio político e pedagógico a ser vencido. 
O IFRN tem, no papel, um Projeto Político Pedagógico (PPP) democrático, participativo e emancipatório extremamente avançado, mas continua sendo uma Instituição escolar administrada por muitas normas, regulamentos, portarias, manuais, horários rígidos que limitam a aplicabilidade do proposto no PPP e da proposta do PROEJA. O estudante da EJA, por sua própria situação de vida "irregular", não consegue atender as exigências legais estabelecidas pela Instituição que ainda não conseguiu conciliar a educação técnica com a humana.

Sabe-se que há várias formas de se conceber a proposta do PROEJA. Por sua própria natureza, não é uma realidade acabada. Por isso, sua implementação não pode estar limitada, apenas, às prescrições legais e aos objetivos dos cursos técnicos de nível médio. Precisa que se entenda a inclusão de estudantes oriundos da Educação de Jovens e Adultos (EJA) a partir de sua própria especificidade, o que exige das Instituições formadoras a transposição de fundamentos teórico-metodológicos e prático-pedagógicos da educação inclusiva para o acolhimento do público da EJA.

É uma nova modalidade de ensino para o IFRN que se configura como um fenômeno humano, histórico e multidimensional que precisa ser repensado em termos de processos inclusivos e acessibilidade total.

O PROEJA propõe para a sala de aula o predomínio dos aspectos humanos da abordagem humanista do processo de ensino e aprendizagem. Está lá, no seu Documento Base, mas as dimensões técnica e cognitiva do processo de ensino têm sido dominantes.

Mas, ainda assim, deve-se insistir que, qualquer que sejam os novos desdobramentos que venham a ser gerados por esses dados, é preciso que a escola comece a tratar os problemas dos estudantes do PROEJA tendo como ponto de partida as necessidades a serem enfrentadas por esses estudantes no seu cotidiano de vida para que uma pedagogia inclusiva seja desenvolvida como forma de política social dentro da escola. É imperioso que se criem formas de análise que não partam do pressuposto de que as experiências vividas pelos estudantes da EJA podem ser automaticamente inferidas a partir de determinações legais.

Mesmo com o desenvolvimento de novas trajetórias práticas dentro da pedagogia do IFRN - Campus Zona Norte é essencial compreender que o poder necessário à transformação da estrutura escolar tradicional numa escola inclusiva não pode ser gerado, apenas, pela mera implantação de determinada proposta teórica imposta na forma de Lei. A reforma educacional, como possibilidade prática de uma escola inclusiva, não existe fora da dinâmica vivida pelos que fazem a escola. É tendo em conta esse entendimento que o PROEJA pode se comprometer com questões de transformação e emancipação, questões essas que combinam conhecimento e crítica, de um lado e de outro, um apelo para a transformação da realidade escolar vigente em benefício dos estudantes da EJA.

Como partícipe do processo de implementação do PROEJA, a esperança é que o Campus Natal Zona Norte como um todo sinta a responsabilidade histórica e social diante desse desafio político e pedagógico imposto pelo PROEJA. Nesse sentido, é preciso (re) aprender e (re) educar o olhar para ver além dos preconceitos e da ignorância para que perceba que a vida, o cotidiano e o 
mundo formam um universo de conhecimentos a serem descobertos e (re) inventados e que a atitude inclusiva pode ensinar muito a todos.

Acredita-se que cada um na sua coletividade e na sua práxis pode e deve estar ressignificando, implementando, enriquecendo e ampliando o cotidiano escolar com seu próprio repertório de saber inclusivo. Os profissionais da educação, com sua própria capacidade de agir pedagogicamente de forma crítica, criativa e acolhedora, podem contribuir para o processo de transformação das escolas tradicionais em escolas inclusivas. Fazem isso ao incorporar fisicamente as pessoas com necessidades especiais, contribuindo para a mudança de paradigmas excludentes e influindo efetivamente na construção de uma escola brasileira inclusiva.

Se a escola olhar em profundidade para as necessidades dos estudantes da EJA como manifestações dos problemas do PROEJA, procurando entender suas histórias, experiências e linguagens como formas particularizadas de produção terão menos dificuldade de entender as diferentes leituras, respostas e comportamentos que os estudantes da EJA exibem.

Uma política de educação inclusiva requer o desenvolvimento de uma pedagogia atenta às histórias, aos sonhos e às experiências que os estudantes trazem para a escola. É começando por essas formas subjetivas que os profissionais da educação críticos poderão desenvolver um conjunto de práticas pedagógicas que confirmem, acolham e desafiem formas contraditórias de inclusão social. Esse pode ser um caminho viável ao sucesso do PROEJA.

\section{REFERÊNCIAS}

1. BRASIL. Congresso Nacional. Constituição Federal da República Federativa do Brasil. 5 de outubro 1988.

2. _. Congresso Nacional. Lei Federal no 9.394. Lei de Diretrizes e Bases da Educação Nacional. 20 de dezembro de 1996.

3. Congresso Nacional. Lei Federal no 4.024 Lei de Diretrizes e Bases da Educação Nacional, 1961.

4. . Congresso Nacional. Lei no. 7.853, de 24 de outubro de 1989. Dispõe sobre o apoio às pessoas portadoras de deficiência, sua integração social, sobre a Coordenadoria Nacional para Integração da Pessoa Portadora de Deficiência (CORDE), institui a tutela jurisdicional de interesses coletivos ou difusos dessas pessoas, disciplina a atuação do Ministério Público, define crimes, e dá outras providências. Disponível em:

<http://www.planalto.gov.br/ccivil/LEIS/L7853.htm>. Acesso em: 20 nov. 2008.

5. _._. Senado Federal/Secretaria de Informações. Decreto no 72.425, de 3 de julho de 1973. Cria o Centro Nacional de Educação Especial (CENESP) e dá outras providências.

6. _. DECRETO № 3.956, DE 8 DE OUTUBRO DE 2001.Promulga a Convenção Internacional para a Eliminação de Todas as Formas de Discriminação contra as Pessoas Portadoras de Deficiência. Disponível em: http://www.planalto.gov.br/ccivil_03/decreto/2001/D3956.htm. Acesso em 21 de dezembro de 2008. 
7. .RESOLUÇÃO CNE/CEB № 2, de 11 de Fevereiro de 2001. Institui Diretrizes Nacionais para a Educação Especial na Educação Básica

8. .Congresso Nacional. Decreto no 3.298/99. Regulamenta a Lei no 7.853, de 24 de outubro de 1989, dispõe sobre a Política Nacional para a Integração da Pessoa Portadora de Deficiência, consolida as normas de proteção, e dá outras providências.

9. .MEC/CEB. Parâmetros Curriculares Nacionais. Brasília, 1998.

10. CENTRO FEDERAL DE EDUCAÇÃO TECNOLÓGICA DO RIO GRANDE DO NORTE. Projeto políticopedagógico do CEFET-RN: um documento em construção. Natal: CEFET-RN, 2005. Disponível em: <http://www.cefetrn.br>. Acesso em: 05 abr. 2008.

<http://portal.mec.gov.br/seesp/arquivos/pdf/salamanca.pdf>. Acesso em: 05 nov. 2008

11. DECLARAÇÃO Mundial sobre Educação para Todos. Satisfação das necessidades básicas de aprendizagem, Jomtien, 1990. Disponível em:

<http://unesdoc.unesco.org/images/0008/000862/086291por.pdf>. Acesso em: 01 jun. 2008.

12. DECLARAÇÃO Universal dos Direitos Humanos. Adotada e proclamada pela resolução 217 A (III) da Assembléia Geral das Nações Unidas em 10 de dezembro de 1948. Disponível em:

<http://www.portal.mec.gov.br/seesp/arquivos/pdf/salamanca.pdf>. Acesso em: 01 jun. 2008.

13. DECLARAÇÃO de Salamanca e Linha de Ação sobre Necessidades Educativas Especiais. Brasília: Corde, 1994. Disponível em:

14. MANTOAN, M. T. E. A integração de pessoas com deficiência: contribuições para uma reflexão sobre o tema. São Paulo: Mennon, 1997.

15. NOGUEIRA, S. M. de A. As grandes conferências da década de 90 , as diretrizes da política educacional e o ensino fundamental: uma abordagem. In: ENSAIO: avaliação e políticas públicas. Rio de Janeiro: Fundação Cesgranrio, v.9. n.33, p.459-474, out./dez, 2001.

16. ORGANIZAÇÃO das Nações Unidas. Resolução ONU no 45/91, de 14 de dezembro de 1990.

17. SEVERINO, A. Filosofia da educação: construindo a cidadania. São Paulo: FTD, 1994.

18. SASSAKI, R. K. Inclusão: construindo uma sociedade para todos. Rio de Janeiro: WVA, 1997.

19. SEVERINO, A. Filosofia da educação: construindo a cidadania. São Paulo: FTD, 1994.

20. SILVA, O. M. da. A epopéia ignorada: a pessoa deficiente na história do mundo de ontem e de hoje. São Paulo: CEDAS, 1987.

21. TRIUIÑOS, A. N. S. Introdução à pesquisa em ciências sociais: a pesquisa qualitativa em educação. São Paulo: Atlas, 1990. 